\title{
Exploring land-use histories of tree-crop landscapes: a cross-site comparison in the Mediterranean Basin
}

\author{
Franziska Wolpert ${ }^{1} \cdot$ Cristina Quintas-Soriano $^{1} \cdot$ Tobias Plieninger $^{1,2}$
}

Received: 7 November 2019 / Accepted: 13 April 2020 / Published online: 2 May 2020

(c) The Author(s) 2020

\begin{abstract}
Agroforestry landscapes in the Mediterranean Basin have emerged in a co-evolution between humans and nature and provide numerous ecosystem services to society. Tree crops are iconic elements of these landscapes and have frequently been managed in a sustainable way over centuries, shaping multifunctional landscapes and local people's cultural identities. However, many Mediterranean tree-crop landscapes are undergoing substantial land-use changes, threatening important ecosystem services as a result. The overarching goal of this study is to explore common and diverging patterns of land-use change across different tree crops (oaks, chestnuts, olives) and contrasting landscapes in the Mediterranean Basin over a 200-year period. Specifically, we aim to: (1) describe the dominant land-use change processes across these three crop types using three exemplary sites per crop; and (2) identify and classify the main drivers that determine these landscapes' land change histories. We find a general acceleration of landscape dynamics and identify expansion, continuity, polarisation, intensification, abandonment and renaissance as dominant processes. Although each landscape history is contextualised, we observe a general trend from multifunctional tree-crop landscapes (expansion) towards intensification or abandonment in the last 70 years. The landscapes of the southern fringe of the Mediterranean Basin show predominant trends towards intensification, while the northern landscapes evolve towards abandonment. The driving forces identified are diverse and interrelated, comprising sets of socio-cultural, political, technical, economic and natural factors. We offer some key lessons for sustainable landscape management in highlighting the undervalued potential of tree crops, the inherent complexity of landscapes, the interdependencies of drivers and the importance of economic and socio-cultural driving forces.
\end{abstract}

Keywords Agroforestry $\cdot$ Driving forces $\cdot$ Land management history $\cdot$ Landscape change $\cdot$ Tree crops $\cdot$ Sustainable landscape management

\section{Introduction}

The landscapes of the Mediterranean Basin are not only shaped by different climatic, topographic and geologic cir-

Handled by José Muñoz-Rojas, Universidade de Évora, Portugal.

Electronic supplementary material The online version of this article (https://doi.org/10.1007/s11625-020-00806-w) contains supplementary material, which is available to authorized users.

Franziska Wolpert

franziska.wolpert@uni-kassel.de

1 Faculty of Organic Agricultural Sciences, University of Kassel, Steinstraße 19, 37213 Witzenhausen, Germany

2 Department of Agricultural Economics and Rural Development, University of Göttingen, Platz der Göttinger Sieben 5, 37073 Göttingen, Germany cumstances but are also strongly interconnected by human culture and common land management practices (Blondel 2006). Mediterranean landscapes have been described as complex and adaptive systems that co-evolve through human-nature interactions, creating the ecological as well as social foundations to provide multiple ecosystem services (Martín-López et al. 2016). Different types of land use as well as various management intensities create a mosaic of diverse landscape types and hence habitats for vast biodiversity (Blondel 2010, UNEP/MAP 2016). In particular, Mediterranean tree-crop systems maintain multiple ecosystem services compared to annual arable agriculture, which 
is disturbance-based and thus often associated with sustainability challenges such as high water run-off rates, net soil loss through erosion and/or nutrient and carbon losses (Crews et al. 2016; Martín-López et al. 2016). The Mediterranean Basin harbours iconic tree-crop landscapes that have been formed by traditional management over centuries (Grove and Rackham 2001). Characteristically, these landscapes consist of scattered trees with a diverse, grazed and/or cultivated understorey, which are often located on nutrient-poor and dry soils and are well-known for their species diversity (Olea and San Miguel-Ayanz 2006). The oak tree-crop landscapes of the Iberian Peninsula, called dehesas in Spain and montados in Portugal, are famous examples of such systems. Other landscape-shaping tree crops in the Mediterranean include pine nuts, chestnuts, beechnuts and olives (Grove and Rackham 2001). These systems are used to obtain multiple goods and services, including food, firewood, leaves and understorey as food for livestock and material for handicraft. Thus, tree-crop landscapes contribute in multiple ways to local people's well-being and play a key role in their cultural identity (Kizos and Koulouri 2006; Infante-Amate and Molina 2013).

In the last few decades, Mediterranean landscapes have frequently experienced polarisation in their development: on the one hand industrialisation and/or intensification of land management, for example through increased inputs of agrochemicals and mechanisation; and on the other hand abandonment of land, for example through the migration of rural people to urban areas (Jones et al. 2011). Both processes may lead to a loss of biodiversity and a decline in the provision of ecosystem services, including important cultural services such as cultural heritage or spiritual and aesthetic values (Bugalho et al. 2011; Plieninger et al. 2016). Sustainable landscape management (i.e. a holistic approach promoting a landscape's long-term capacity to provide a variety of ecosystem services) represents one major approach to addressing these pressures, and agroforestry especially has recently received growing scientific and policy interest as part of broader sustainable landscape management strategies (Plieninger et al. 2015; Sanz et al. 2017).

An important foundation of future-oriented landscape management strategies is a thorough understanding of past land-use systems (Antrop 2005; Black et al. 1998; Palang et al. 2005). In particular, a better knowledge of past treecrop landscapes and their dynamics may offer inspiration for future decisions on Mediterranean land uses. Comparisons of historical approaches are increasingly used to inform landscape science and practice (e.g. Acha and Newing 2015). However, there is a research gap in cross-site comparisons to investigate landscape histories and the driving forces of landscape change over longer time frames (Frattaroli et al. 2014; Jepsen et al. 2015). Furthermore, knowledge about the complex interactions of socio-cultural, political, technical, economic and natural drivers remains scant (Bürgi et al. 2004; Plieninger et al. 2016). Therefore, this study aims to provide knowledge and insights into the complexity of landscape history. We analyse the landscape histories of the last 200 years for three key Mediterranean tree crops (olives, cork and chestnuts) in three contrasting Mediterranean landscapes. Our specific goals are to: (1) explore the history of change processes in tree-crop landscapes through the development of narratives; and (2) identify and classify the main drivers of change acting on these landscapes. Finally, we discuss and derive a series of key lessons for sustainable landscape management.

\section{Methods}

\section{Tree crops in the Mediterranean region}

We selected three iconic tree crops of the Mediterranean region that shape landscapes, represent important resources for human subsistence and have been sustained over a long time span, namely cork oaks (Quercus suber), chestnuts (Castanea sativa) and olives (Olea europea) (Fig. 1). These landscapes represent a wide range of land-use intensities and are closely interwoven with the socio-economic and cultural histories of the people living in these landscapes.

Cork oak is limited to the Western Mediterranean Basin (Stockwell 1947). The landscapes are characterised by widespread pastures with scattered oak trees, occurring either in pure stands or mixed with holm oaks (Quercus ilex). Cork oaks have been grown for multiple uses, but the main and most desirable product is the outer bark of the tree. It can be harvested every nine years and is regenerated in that time by the tree. Cork oak is adapted to poor and dry soil conditions but demands a lot of light and is therefore naturally replaced by other trees as soon as light becomes scarce (Grove and Rackham 2001).

Chestnuts are long-lived trees that are often landscapeforming. Their high yield and their nutrient composition facilitate their use as a staple food as an alternative to grain. Therefore, in many cultures chestnuts are referred to as 'bread trees' (Tagliaferri and Di Lonardo 2016). Their fruits are often used as food, their wood for construction and heating and the tannic acid they contain for tanning leather (Perry 1967).

Olives are assumed to be the most traditional tree crop in the Mediterranean Basin. In fact, the existence of olive trees was frequently used to define the border of the Mediterranean region. From antiquity to the present day, olive cultivation has been widespread and has shaped many cultural landscapes in this area (Cecchini et al. 2019). Olives have formed the basis of many people's livelihoods, most notably by providing olive oil (Kizos and Koulouri 2006). 


\section{Landscape and literature selection}

For each crop, we chose three landscapes distributed across different countries and dominated by the respective crop. We selected these landscapes and the corresponding literature as follows. In the first step, we searched the Web of Science and Google Scholar databases for each tree crop in combination with the different Mediterranean countries (i.e. we searched for "chestnut" and "Spain") to identify potential case study landscapes in the countries of the Mediterranean Basin. We chose the landscapes to identify landscape change processes and driving forces and examined the suitability of available publications for that purpose. We selected the landscapes with the best availability of literature on landscape history as our case studies. In the second step, we used the same databases to search for the keyword combination "landscape" and "crop" (i.e. we searched for "chestnut" and "Corsica" and worked through the first 200 studies returned by Google Scholar and all studies found in the Web of Science). We complemented the findings with relevant literature from the previous search as well as by snowballing. We used the framework of driving forces (short: drivers) to describe the reasons behind landscape change (cf. Bürgi et al. 2004) and diligently selected four to six key papers to compile regional landscape histories. We prioritised publications by different authors over multiple publications by the same author but ultimately selected those publications with the most relevance. We chose contrasting landscape histories regarding the main processes and drivers and covered as many different countries and cultures as possible. To do so, we picked one Southern Mediterranean country and two Northern Mediterranean ones for each crop (Fig. 2). Given that literature for the southern fringe of the Mediterranean Basin was scant, we additionally conducted one expert interview (with university-based experts with profound knowledge of the particular crop and landscape) for each of the three landscapes. The case study regions for cork landscapes were Alentejo in Portugal, the KroumerieMogod Mountains in Tunisia and Extremadura in Spain. The chestnut landscapes comprised Corsica in France, the Northern Apennines in Italy and the Aegean region of Turkey. For olive landscapes, we chose Lesvos in Greece, Baena in Spain and the Rif region of Morocco. Interpretations of the boundaries of each landscape were based on the information and spatial references of the primary publications. In our cases, the landscapes were either defined by administrative units or by natural borders (Table 1).

The focus of our research was on the landscape scale, but we considered drivers of different scales from local to global levels. We chose a time span from 1800 to the present, as this represents a relatively long time frame for which good evidence is available. Indeed, short time frames are disadvantageous because it is difficult to differentiate between parallel occurring drivers and their effects (Jepsen et al. 2015).

\section{Landscape histories, processes and driving forces}

We first compiled a model narrative for one of the landscapes. This template was then used to compile narratives for all nine study landscapes (see Supplementary Material). Once these were written and harmonised among each other, we started a more systematic approach of classifying changes into processes and categorising drivers. For each landscape and period, we synthesised the main process and the main driving forces behind it and compiled a summary of each of the landscape narratives.

A landscape process is defined here as the time period in which the landscape (shaped by a tree crop) undergoes a specific prevalent process related to the main crop. For example, if the extent of the chestnut landscape increases on Corsica, the landscape process of Corsica in that time period is "expansion". We must emphasise that a landscape does not exist as a fixed state, but rather is always in a co-evolving process of humans and nature and therefore can be defined as a "process". The turning point from one "process" to another is the moment at which there is a shift in the prevalence of the process. We illustrated the
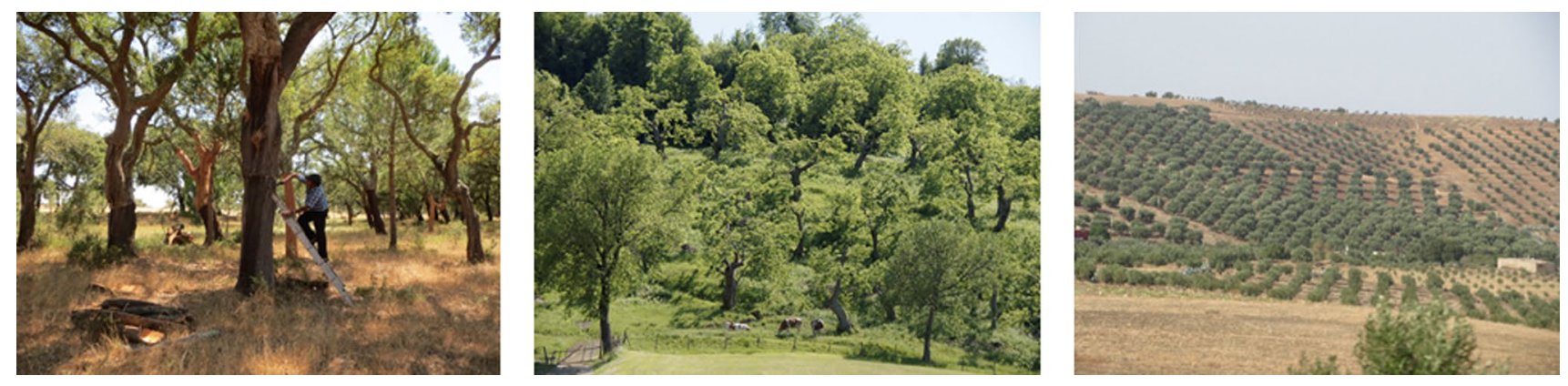

Fig. 1 Examples of tree-crop landscapes in the Mediterranean Basin. Left: Cork oak landscape in Alentejo, Portugal (picture by Tobias Plieninger); Centre: Chestnut landscape in the Northern Apennines, Italy (picture by Johannes Schantl); Right: Olive landscape in the Rif region of Morocco (picture by Tobias Plieninger) 
Fig. 2 Location of the nine tree-crop landscapes across the Mediterranean Basin

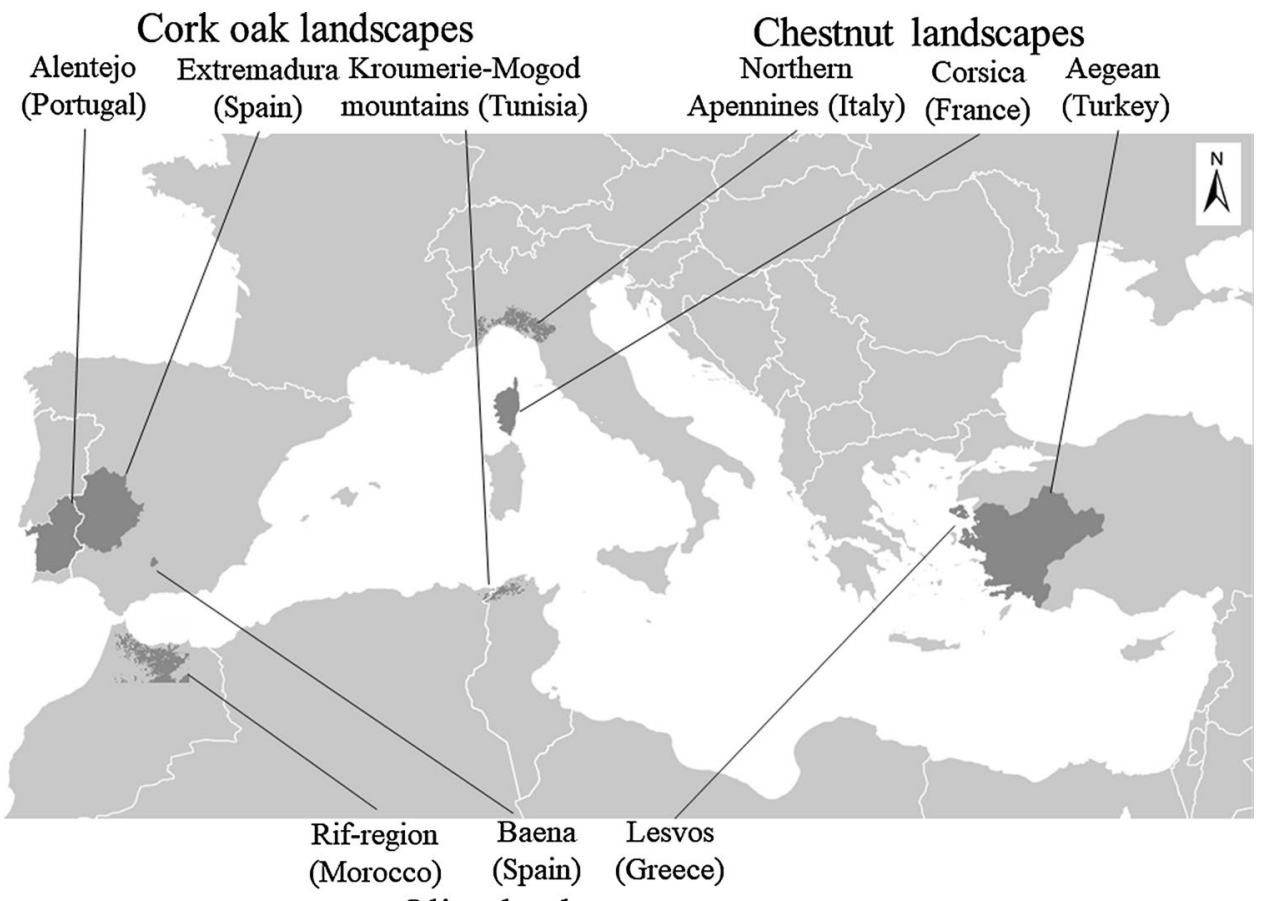

Olive landscapes landscape processes in a timeline to explore differences as well as common patterns across distinct landscapes.

For each landscape process, we extracted the driving forces and depicted them in a table. We used five categories of drivers: socio-cultural, technical, political, economic and natural (modified from Bürgi et al. 2004). For each of the six landscape processes, we evaluated the proportional contribution of each category of driving forces to the process. As an example, we considered all processes of "abandonment" across all landscapes and examined the proportion of natural driving forces compared to the other categories. This enabled us to ascertain whether there was any pattern in the distribution of drivers regarding the processes. The results are displayed in the following ways: (a) short summaries of the nine landscape histories; (b) systematic comparison of the change processes in different periods; and (c) systematic comparison of the driving forces of landscape change.

\section{Results}

Nine comprehensive narratives of tree-crop landscape histories serve as the basis for the compiled narratives summarising the main processes and driving forces of landscape change (Supplementary Material).

\section{Tree-crop landscapes}

\section{Cork oak cultivation}

Cork oak in Alentejo, Portugal Before 1820, cork oaks did not play a major role for people in Alentejo. From the 1820 s to the 1950 s, the cork oak landscape (called montado) underwent a period of expansion, promoted by the liberalisation of the markets. Multiple demands on the use of cork landscapes and new technological advancements in the cork processing sector enhanced the profitability of the montados for land managers. At this time, the montados shaped people's cultural identity. In the period from 1950 to the present, there was a polarisation of land use in the cork oak landscape: market liberalisation and the resultant decline in profitability led to the abandonment of less productive sites, whereas the most productive sites were cultivated even more intensively. These developments were additionally fostered by the use of agrochemicals and the over-exploitation of the landscape. A labour shortage due to outmigration further accelerated this evolution. In particular, in recent years droughts and pests have applied further pressures on the cork oak landscapes.

Cork oak in Extremadura, Spain Cork oak landscapes constitute a traditional form of land use in Spain and have been used for multiple goods as a major source of livelihoods. 
In the period from the 1800 s to the 1950 s, the cork oak landscape of Extremadura expanded. Among other reasons, the turmoil that resulted from the Napoleonic Wars and the associated abandonment of the pastures facilitated cork oak's expansion in south-western Spain, as the absence of livestock allowed young cork oaks to become established. Moreover, the over-exploitation of other crops like vines leached the soil and necessitated the use of less demanding crops like cork. The rising demand for cork combined with market liberalisation increased the profitability of cork production in the second half of the nineteenth century. Population growth as well as a privatisation wave further fostered this evolution in the first half of the twentieth century. However, the situation changed from the 1950s to the 1990s with the polarisation of land use, primarily driven by industrialisation (e.g. the input of agrochemicals) and the related loss of profitability of traditional production. During this period, fertile areas were intensified and often converted to intensive agricultural croplands, whereas steeper and unfertile areas were abandoned. Outmigration led to even greater polarisation. However, agricultural subsidies supported cork production and some conservation measures prohibited tree felling which, despite some considerable losses, ultimately saved vast areas of cork oak landscape. The renaissance of the cork oak landscape began in the 1990s and is still taking place today. It has been driven by conservation programmes that support the traditional management and replanting of oak trees. Nowadays, new marketing strategies, such as the labelling of "organic agriculture" or a "protected designation of origin", further enhance the profitability of other landscape products like ham while contributing to multifunctionality.

\section{Cork oak in the Kroumerie-Mogod Mountains, Tunisia Tuni-} sia's cork oak history is rather young: cork oak landscapes were planted around 1860 and were first harvested in the 1880s. The land covered by cork oak (and therefore also the exploited cork) is state-owned. Nevertheless, these landscapes have offered multiple goods and subsistence to locals. The 1930s until the 1950s saw the intensification and the over-exploitation of the cork landscape, driven by new government restrictions on what was previously free utilisation (e.g. of firewood) by locals. These restrictions as well as droughts threatened local livelihoods and led to the disregard of these laws. Since the 1950s, there has been an ongoing decline of cork oak landscapes, mainly driven by population increase connected with over-exploitation, which has prevented tree and grass regeneration. Given that locals are allowed to engage in grazing, there has been an ongoing conversion to treeless rangelands. Furthermore, natural forces like droughts and fire have played a major role as driving forces of abandonment.

\section{Chestnut cultivation}

Chestnuts in Corsica, France In Corsica, chestnuts have not only represented a natural resource for multiple purposes and a key component of local livelihoods, but also an important part of cultural identity, expressed for example through the traditional craft products developed by local people. French rule aimed to defame chestnuts as a staple food. It labelled chestnut as "the food of laziness" and restricted chestnut growing to undermine Corsicans' quest for independence. However, this restriction did not stop the cultivation of chestnuts and ultimately made Corsicans more aware of their independence from global food systems. Chestnut cultivation became a symbol of resistance and Corsican freedom. From the 1850s, the chestnut culture collapsed and chestnut cultivation was increasingly abandoned for multiple reasons. One driver was the changing lifestyle of the people on the French mainland and the desire of Corsicans to adapt to this. An outmigration wave commenced, resulting in Corsicans migrating to the French mainland and other European countries. World War 1st and 2nd led to worker shortages for the harvest season. In addition, chestnut diseases (mainly chestnut blight and ink disease) reduced the number of chestnut stands, while economic profitability suffered from the opening up of the market and resultant greater competition. During the 1980s, the chestnut landscape began to undergo a period of renaissance, driven by local initiatives that revived the chestnut culture and the related economy, buttressed by technological progress in processing (e.g. shell-opening machines). To date, there have been tensions between the aim of multifunctional and diverse traditional systems and less diverse, economically more profitable production systems, the former often being more labour-intensive.

Chestnuts in the Northern Apennines, Italy Traditional culture in the Northern Apennines has been closely linked to chestnut cultivation as a staple crop. The entirety of the nineteenth century was a period of the expansion of chestnut cultivation, driven by population growth. In this region, chestnuts were grown for multiple uses (e.g. food, fodder for animals, heating) within subsistence agriculture, but also constituted a profitable trading good. From the 1900s until the present day, a period of abandonment of the chestnut landscape emerged, driven by multiple forces. Increasing pest pressure and hence high tree damage and yield losses have led to a reduction in profitability. Simultaneously, the changing lifestyle of the local population has led to outmigration and a loss of interest in chestnut cultivation. In the last decade, the preservation of local knowledge about chestnut management and the prevalence of cultural connections to chestnuts as well as rising consumer interest have given hope for a renaissance of the chestnut culture and landscape. 
Chestnuts in the Aegean region, Turkey From ancient times up to the middle of the twentieth century, chestnut landscapes prospered in the Aegean region of Turkey. They contributed as a profitable good to locals' livelihoods for multiple purposes, such as by constituting an importance source of food, timber and honey. However, since the beginning of the twenty-first century, the land use of chestnut stands became polarised across the region. The demand for chestnuts in Turkey was higher than the supply, but it was risky to plant traditional chestnut trees that are not resistant to widespread diseases. High demand for chestnuts led to a transformation of chestnut landscapes to industrial production as well as the abandonment of marginal areas owing to a lack of profitability. To control the diseases that were threatening chestnut cultivation, the state restricted the management of chestnuts to local people in nature reserves. However, this prevented people from removing infested trees, which enhanced the spread of the disease problems and further instigated abandonment. Although local people have increased the sustainability of chestnut stands by developing small-scale agriculture and fostering tree health, more work-intensive, small-scale agriculture is no longer profitable because of the competition posed by global markets. This presents an uncertain future for the conservation of these landscapes.

\section{Olive crop landscapes}

Olives on Lesvos, Greece On the Greek island of Lesvos, olive cultivation expanded from 1800 until the 1920s. At this time economic development and population growth combined with high demand for olive oil promoted olive cultivation. Technological developments in the transport sector supported this evolution, meeting overseas demand. An intensification process of olive land use started in the 1920s and persisted until the 1970s. It was driven by an economic crisis and associated outmigration to the mainland. Unlike other land uses (e.g. annual crop cultivation), olive production remained in demand and profitable. However, the use was specialised on olive oil production instead of multiple demands. Since the 1970s, olive cultivation is no longer profitable. Therefore, there has been an ongoing abandonment process, driven by the low profitability of olive cultivation and reinforced by an economic crisis, outmigration and a lack of appreciation of farming related to a changing lifestyle. However, this process has been somewhat offset by the cultural connectedness of farmers to their olive trees, continuing to grow them despite their uncertain profitability.

Olives in Baena, Spain In the period 1800-1820, olive growing continued as before, representing an aspect of local livelihoods and an important tree species within diverse agroforestry systems. From the 1820 s to the 1930s, olive cultivation was intensified and expanded simultaneously. This process was fostered by the liberalisation of global markets and a resulting economic crisis. Olives were valued for their versatility (e.g. table olives, olive oil, fodder for animals, wood) as well as general demand in global markets, increasing their profitability. These developments were further reinforced by the privatisation of land, population growth and the mechanisation of land management. In the period from 1936 to 1975, the disorder of the Spanish Civil War led to the temporary abandonment of olive cultivation. From 1975 until the present day, there has been a second wave of intensification and expansion of olive cultivation, bringing large-scale olive monocultures to the contemporary landscape of Baena with a particular emphasis on olive oil production. This process has been driven by high demand for olive oil and the considerable profitability of olive cultivation, reinforced by subsidies. Mechanisation and the input of agrochemicals have also increased in recent decades.

Olives in the Rif region, Morocco As a staple food source, olive landscapes have continuously contributed to the livelihoods of local people in the Rif region of northern Morocco. In this region, olives have been used for multiple purposes, such as for fruit consumption, oil, wood harvesting for heating and as a fodder source for livestock. From the 1910s, olive cultivation expanded due to the privatisation of land and as people converted forests into olive agroforestry systems, fearing that political will would transform their forests into state- or public-owned land. From 1956 the olive landscape of northern Morocco underwent a process of intensification. The main driving force was the global demand for olive oil and the Moroccan government's running and financing of programmes to enhance olive production to supply global markets. However, industrialisation and the specialisation on olive oil production have engendered various problems, such as vitality losses of olive trees and lower productivity, for example the fact that tree nurseries cut the tap-roots, which does not allow the trees to reach groundwater.

\section{Processes of landscape change}

We have identified and characterised six distinct processes of change in the chosen Mediterranean landscapes:

- Expansion. A tree-crop landscape that is flourishing and growing in its extent as well as in its importance for human use.

- Continuity. A landscape that is not significantly changing but rather remaining in the same state over a period of time. The tree crop is either still one of many trees or 
already enjoys a certain level of importance, depending on the landscape.

- Polarisation. Concurrent processes of abandonment on less fertile, steeper places as well as intensification on fertile zones.

- Abandonment. A tree-crop landscape that is undergoing a process of decreasing inputs as well as outputs.

- Intensification. A tree-crop landscape whose management has resulted in an increased yield per area. This often but does not necessarily coincide with an intensified use of industrial inputs, such as machinery and agrochemicals.

- Renaissance. The process of returning to expansion following a phase of abandonment, intensification or polarisation.

Figure 3 shows the different processes for each of the nine landscapes between 1800 and the present. A general trend that has been observed was an increased dynamic in land change processes in the last century compared to previously. It is noteworthy that in all landscapes, sooner or later there was a time of expansion. However, this process was interrupted by either abandonment, intensification or both (polarisation) between 1850 and 1970. Recently, the cork landscape in Extremadura and the chestnut landscape in Corsica have evolved towards renaissance.

\section{Driving forces}

Table 2 shows the main driving forces for each period in which a certain process has proved prevalent in each of the nine landscapes. Some drivers have repeatedly led to particular processes. The profitability of the crop for land managers, population growth, multiple demands for tree uses (e.g. food, timber, fodder), being a part of local livelihoods and shaping cultural identities have represented the main drivers of expansion. However, uncommon reasons for the expansion of a tree-crop landscape have also emerged, such as in Morocco, where political reforms and community decisions have led to the expansion of the olive landscape, even though most people would prefer a landscape with more diverse agroforestry systems.

Pests and diseases stand out as a very severe driver as they have always been accompanied by reduced profitability or an economic crisis and have mainly affected chestnut landscapes. While population growth has often seemed to be a driver of expansion, outmigration has typically led to the abandonment. Missing profitability, agrochemicals, market liberalisation, outmigration, pests and diseases as well as land-use restrictions have proved to be the main drivers of polarisation. The simplification of land use has often led to a process of intensification, but it can also drive abandonment. Most processes have been driven by multiple interrelated factors, although for some only a few or even just one driving force has been responsible (e.g. the abandonment of the olive landscape in Spain was the result of the Civil War). Counterintuitively, war may lead to a rise (expansion) and a fall (abandonment) of a landscape, as seen for the olive landscape in Baena, Spain (abandonment) and the cork oak landscape in Extremadura, Spain (expansion).

We can allocate the driving forces into five categories: socio-cultural, political, technical, economic and natural. The socio-cultural category contains the highest number of individual drivers, followed by political and economic drivers. Natural and technical drivers present a smaller number of individual drivers (Table 3 ).

For each of the six landscape processes (i.e. expansion, continuity, polarisation, intensification, abandonment, renaissance) we may depict the proportional contribution of the driving force categories to the process of landscape change (Fig. 4). Socio-cultural drivers have played a major role across the six landscape processes. This is particularly the case for continuity, expansion and abandonment. Technical drivers have not emerged as drivers for continuity and abandonment, whereas natural driving forces only contribute to abandonment, polarisation and intensification.

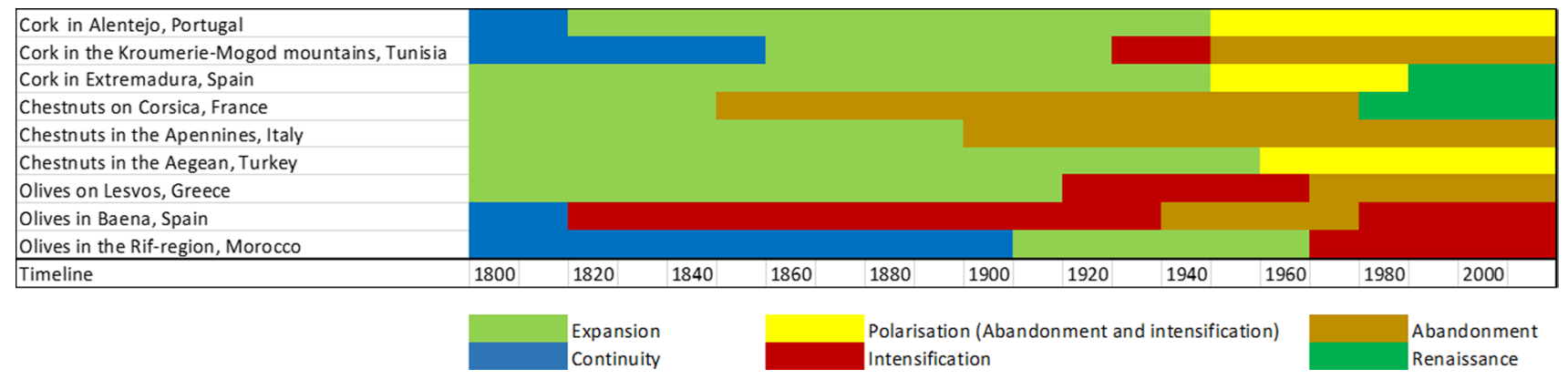

Fig. 3 Historical periods of the nine tree-crop landscapes from 1800 until present 


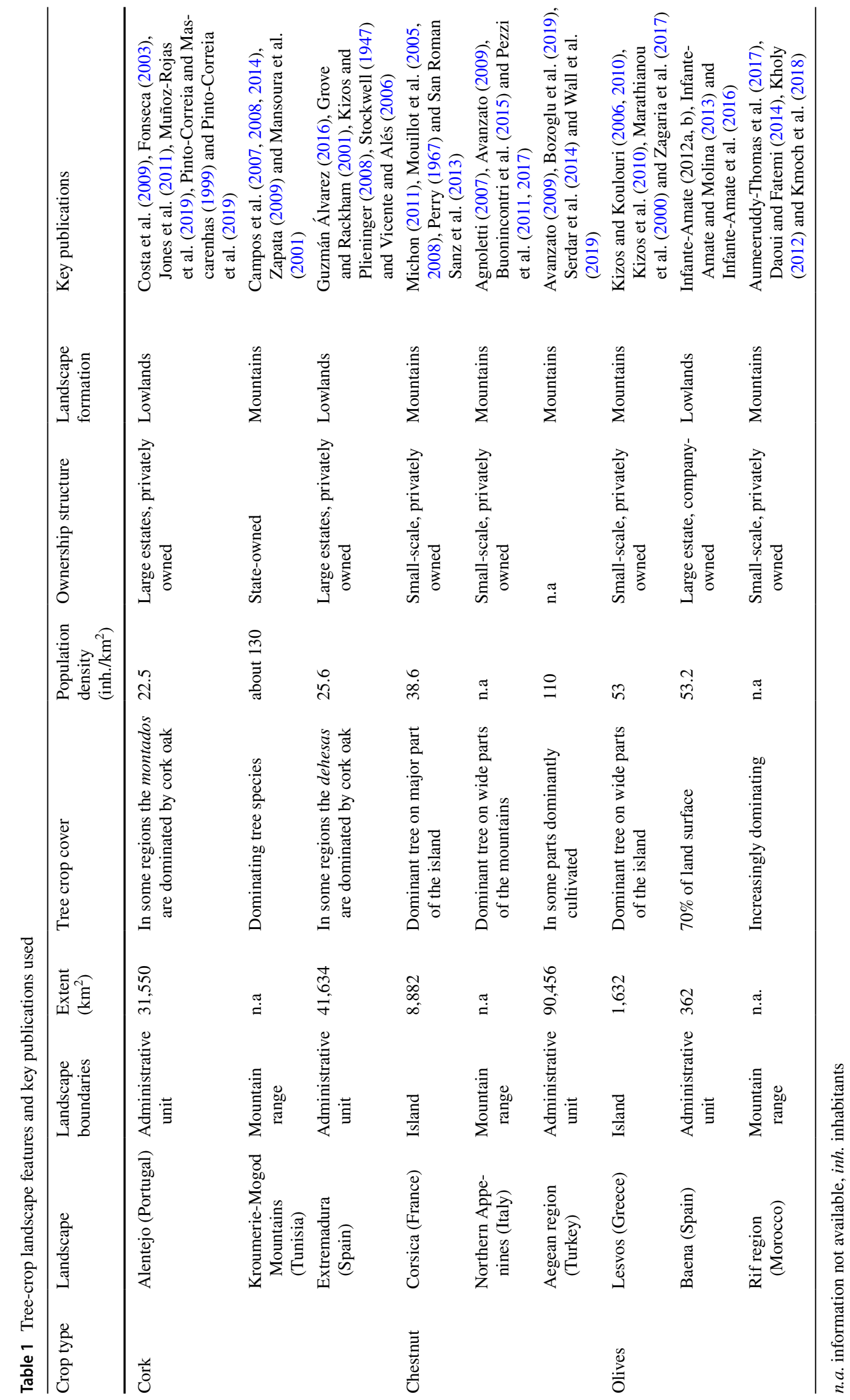




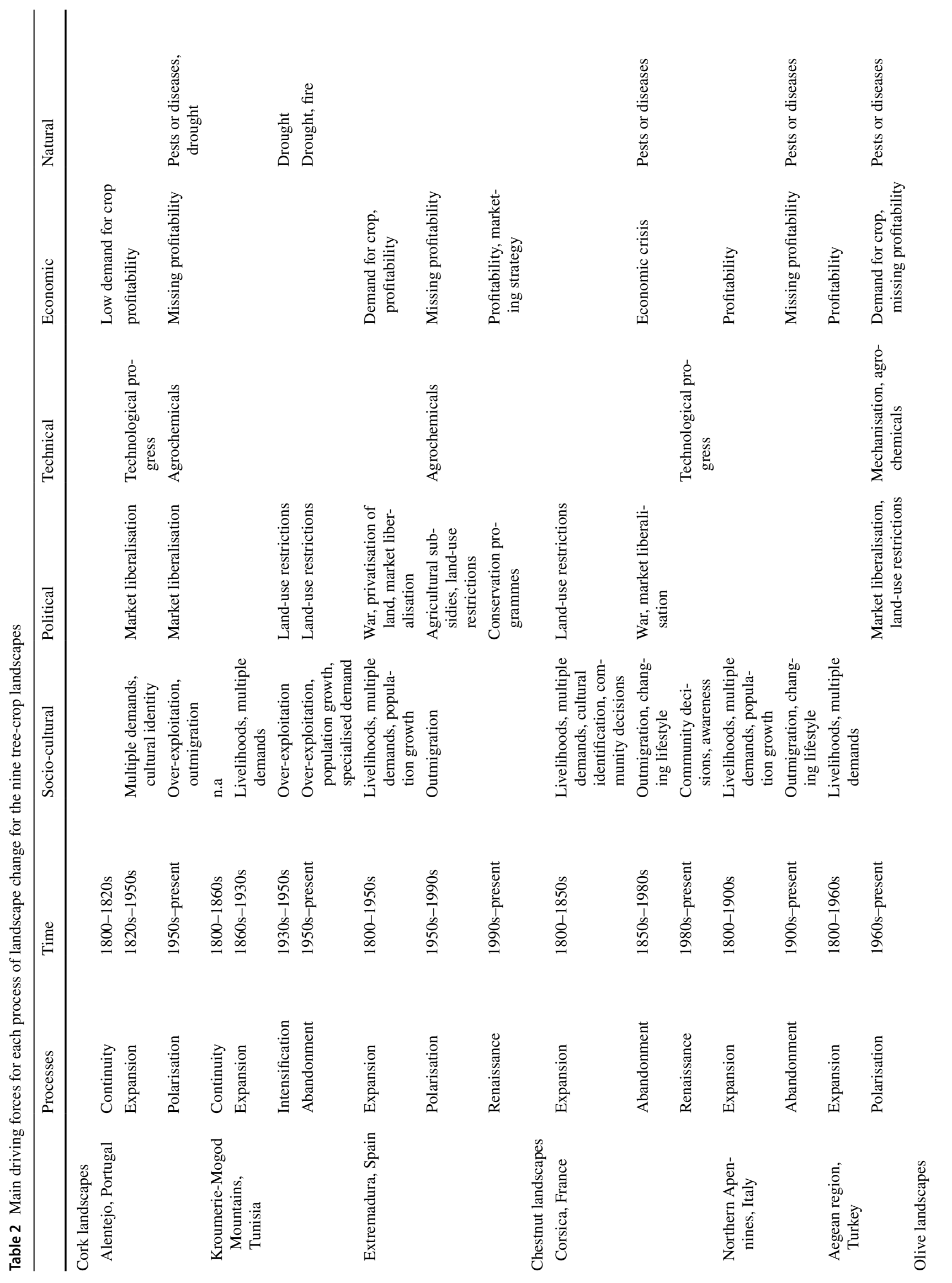




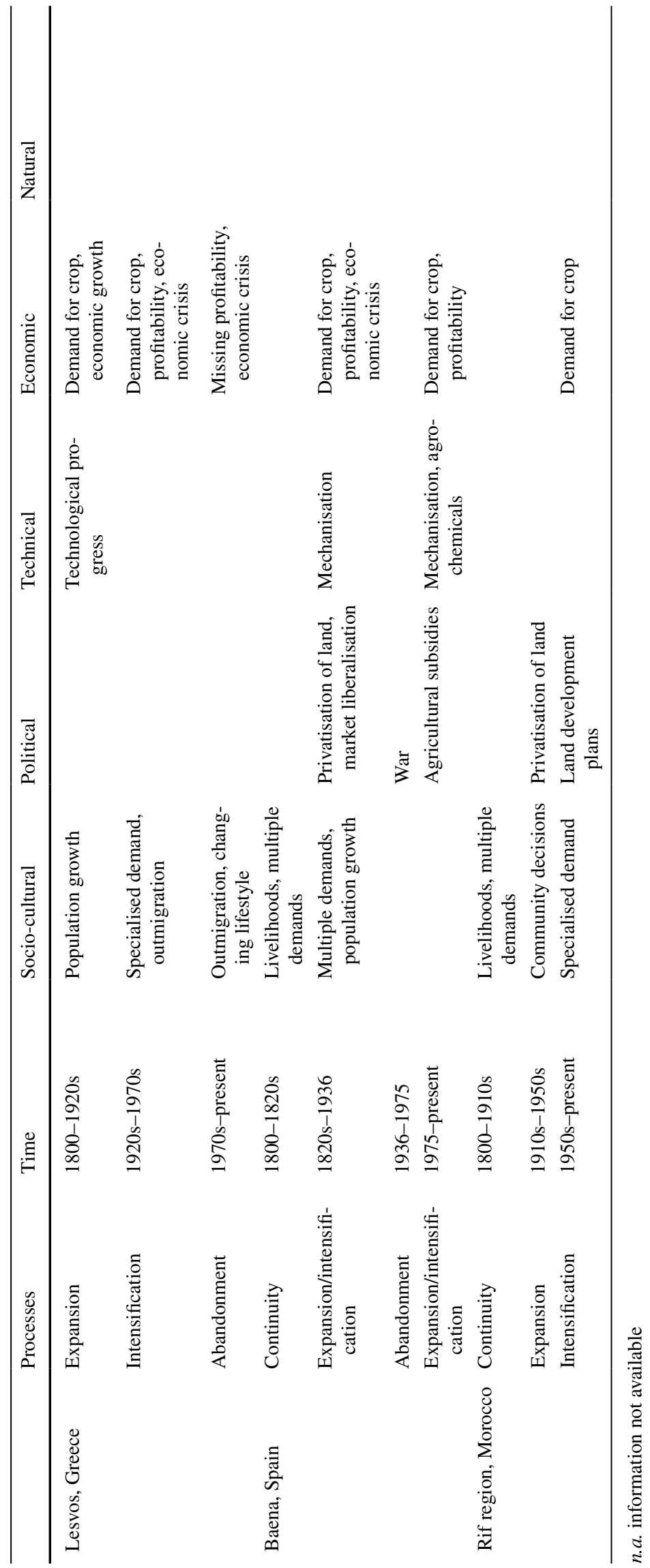


Table 3 Categorisation of drivers of landscape change

\begin{tabular}{llll}
\hline $\begin{array}{l}\text { Type of drivers } \\
\text { Socio-cultural }\end{array}$ & Political & Technical & Economic \\
\hline Over-exploitation & Land development plans & Technological progress & Low demand for crop \\
Livelihoods & War & Mechanisation & Demand for crop \\
Multiple demands & Privatisation of land & Agrochemicals & Missing profitability \\
Specialised demand & Market liberalisation & & Profitability \\
Population growth & Land-use restrictions & & Marketing strategy \\
Outmigration & Agricultural subsidies & & Economic crisis \\
Changing lifestyle & Conservation programmes & & Economic growth \\
Cultural identification & & & \\
Community decisions & & & \\
Awareness & & & \\
\hline
\end{tabular}

\section{Discussion}

While sustainable landscape management is a forwardlooking planning practice, considerable knowledge can be derived for sustainability by focusing on past landscape evolutions. From 1800 to the present, the Mediterranean landscapes analysed in this study generally evolved from expansion towards either abandonment or intensification and showed increased spatial and temporal dynamics. Our results (Fig. 3) show common patterns among the crops: Olive systems tended to be intensified, chestnut systems were generally abandoned and cork was rather polarised between intensification and abandonment in the last 70 years. The landscapes in the northern fringe of the Mediterranean Basin have shown a tendency of abandonment due to outmigration from rural areas. The decline of agricultural population is a typical phenomenon of the northern Mediterranean fringe (Benoit and Comeau 2005). By contrast, the landscapes of the southern fringe have faced considerable population pressure. The driving forces behind these landscape changes are diverse. However, they can be categorised into socio-cultural, political, technical, economic and natural drivers. Remarkably, socio-cultural drivers have played a major role in most land-use change processes.

Besides the individual landscape histories and their driving forces, a pattern can be discerned in most of the landscape histories: The landscapes faced multiple demands, by being (for instance) sources of food, fodder and wood, rendering them an important part of local people's livelihoods. During the course of the nineteenth and especially the twentieth centuries, there was a substantial decline in traditional land uses due to the overall industrialisation of agriculture (mechanisation, agrochemicals) and the reduced profitability of traditional systems, resulting in either intensification or abandonment. However, local people's cultural associations and initiatives have emerged, valuing cultural heritage and contributing to its recovery. A similar history has been identified for other tree crops, such as in almond landscapes in the Apennines in Italy by Frattaroli et al. (2014).

\section{Landscape processes}

We have noted a common trajectory from an expanding, multifunctional landscape towards either intensified or abandoned systems, similar to Pinto-Correia and Vos (2004). This polarisation has largely occurred due to market liberalisation and the related competition among goods. Market liberalisation in most cases has brought about a loss of profitability, due to the presence of competition among suppliers from different contexts, such as climatic and soil conditions, labour costs and political restrictions. However, in the case of cork oak cultivation, which is only distributed in the Western Mediterranean region, market liberalisation has had a positive effect, especially because a product like cork can neither be produced in a different climate nor in a more industrialised production system.

Our landscape histories demonstrate the overall increased dynamics of landscape processes in the second half of the studied period, as additionally observed by Jepsen et al. (2015). This may partly be an artefact due to a lack of documentation in the past, but also an expression of an actual increase in land-use dynamics. We have found that in most cases the transition from one process to another was not aligned among different landscapes. The land-use regimes of the European case studies show more homogeneous patterns of change from one regime to the next. We assume that we can cover more individual trajectories at a landscape scale compared to a national scale (Jepsen et al. 2015). There may also be distinct time lags between land-use regimes and actual visibility in the different landscapes.

The common trajectory of a trend towards polarisation can be broken down into trends among the different tree-crop 
Fig. 4 Driving forces that shape the processes of landscape change. The $y$-axis refers to the percentage of drivers contributing to the processes of land-use change

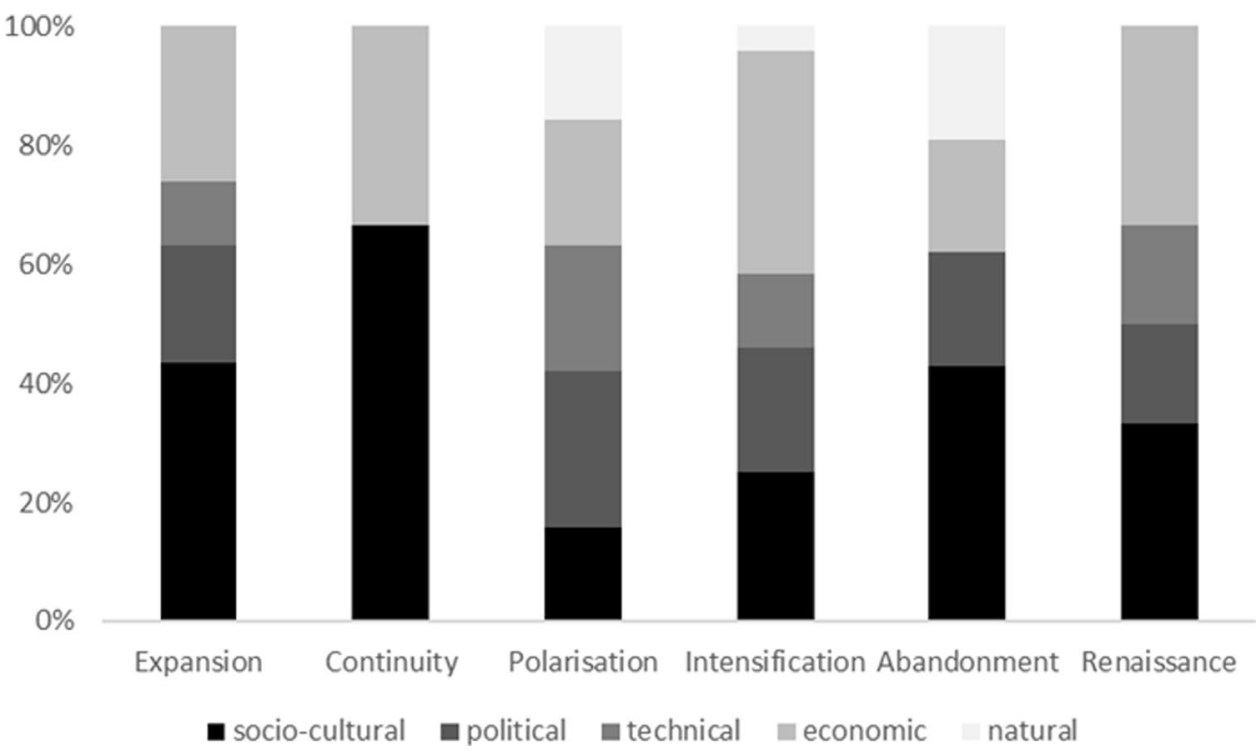

landscapes for olives, chestnuts and cork oaks. The main process of chestnut landscapes in the nineteenth century was expansion, as chestnut culture has a long and widespread history (Avanzato 2009), while the importance of olives and cork mainly developed in the twentieth century. In olive landscapes, intensification has been a prevalent process over the last 70 years, driven by the combination of high demand for olive oil and the fact that olives can be grown in intensified systems (cf. the olive landscape in Baena). By contrast and despite high demand, chestnut systems have been largely abandoned over the past century, primarily due to diseases. Cork landscapes have exhibited especially polarised landuse patterns (i.e. intensification and abandonment). Such polarisation of cork landscapes in Portugal and Spain has in both cases been driven by the overall industrialisation of agriculture and hence the intensification of more profitable sites as well as the abandonment of marginal sites. The driving forces behind the process of abandonment of the Tunisian cork landscapes have been governmental land-use restrictions aimed at counteracting over-exploitation.

We can see a tendency of the landscape processes in the northern fringe of the Mediterranean Basin to move towards abandonment and renaissance. Abandonment has occurred in the olive landscape on Lesvos as well as the chestnut landscapes in the Northern Apennines due to the outmigration of local people. Renaissance has been observed in the case of the cork oaks in Extremadura and the chestnuts in Corsica owing to regained profitability, but also awareness and conservation programmes. The cork oak landscape in Alentejo has undergone a process of polarisation, whereas the olive landscape in Baena fails to fit this pattern. Indeed, this landscape represents a very special case as it is the only one that has undergone expansion and intensification simultaneously and that also did not start as a cultural landscape.
The landscapes of the southern fringe have generally been focused on intensification, buttressed by a rising demand for food due to a rapidly growing population (Benoit and Comeau 2005; Zdruli 2014). We can observe intensification in the olive landscape of Morocco and polarisation in the chestnut landscape of Turkey. The abandonment process in Tunisia can be understood if the context is considered: high population pressure has led to over-exploitation, resulting in local people's restricted use and hence abandonment.

\section{Driving forces of landscape change}

We have found that most of the landscape processes are influenced by multiple interrelated driving forces that can be categorised as socio-cultural, political, technical, economic and natural.

Socio-cultural factors are important drivers of change and are essential for expansion and renaissance to occur. Similarly, a review of driving forces of landscape change across Europe has identified cultural drivers as a key reason for rural development activities (Plieninger et al. 2016). Multiple demands for the use of a tree-crop landscape are tending to lead landscapes towards expansion. However, the opposite trend - the intensified exploitation of a single crop-has led to landscape simplification. Socio-cultural drivers enjoy considerable importance in landscape management because they are prevalent in all landscape processes and usually play the dominant role. However, there is no evidence of their actual proportional contribution to decision making, which might, therefore, be investigated in future research via interviews regarding people's perceptions.

Political drivers do not only influence the legal frame in which a landscape develops but also directly determine profitability for land managers through subsidies (cf. Table 2). 
Agricultural subsidies are usually named among the political drivers and have contributed to both intensification and abandonment. Land-use restrictions also play an important role and seem to instigate polarisation. This is supported by the European review on driving forces, where political drivers have appeared most often as a driver for intensification and represent the second-most common driver of abandonment (Plieninger et al. 2016).

In terms of technical driving forces, agrochemicals emerged most often, followed by mechanisation and technological progress, indicating an industrialisation of agriculture. Technical drivers seem to enjoy considerable importance in the case of polarisation of a landscape, but surprisingly no technical drivers were found to lead to abandonment. However, indirectly the technical opportunities for industrial intensification fostered the abandonment of less productive and particularly steeper slopes that cannot be managed as mechanised systems (Lasanta et al. 2017; Strijker 2005).

Economic drivers, in particular profitability or missing profitability, represent major drivers of landscape management, as it is necessary for people to make an income from the land. Therefore, missing profitability mostly leads to abandonment, whereas profitability fosters expansion, intensification and renaissance. The demand (or low demand) for a crop is closely connected to its profitability, as the two rise or fall together.

In general, natural drivers rarely appear, but within these, pests or diseases and droughts are prominently mentioned in the literature included within this study. Natural drivers play an important role in processes of abandonment and polarisation but not for expansion and scarcely for intensification. They mainly reflect negative aspects such as catastrophic events. Pests and diseases are very influential, especially for chestnuts. Traditional chestnut landscapes consist of pure Castanea sativa trees that are not resistant to diseases like chestnut blight, whereas Castanea sativa that is interbred with Castanea crenata and/or Castanea molissima can show resistance (Ramos Guedes-Lafargue et al. 2005). Pests and diseases determine the yield and thus people's livelihoods as well as the profitability of land management.

\section{What is the future of Mediterranean landscapes?}

Today, external shocks seem to be on the rise: the pressures posed by pests have increased due to globalisation and landscape simplification (Roossinck and García-Arenal 2015; Rusch et al. 2016), the prices of cork, chestnut and olive products are dependent on the world market and extreme weather events are expected to increase in magnitude and frequency, including droughts in the Mediterranean Basin (Beniston et al. 2007). Most contemporary forms of land use are unsustainable, as they are unable to maintain the multiple societal values of Mediterranean landscapes, such as biodiversity, food security, wood, aesthetic value and recreation for future generations (McIntyre 2008; Kremen et al. 2012). Our landscape histories demonstrate that tree-crop landscapes have met many of these needs in the past and seem to have considerable potential to meet current and future challenges (Hernández-Morcillo et al. 2018; Howlett et al. 2011). In fact, most of the renaissance activities in the treecrop landscapes have been driven by cultural values such as tourism, outdoor recreation or sense of place. Nevertheless, these often fail to lead to increased profitability for land managers (Flinzberger et al. 2020). With the Mediterranean Basin being heavily affected by climate change, tree-crop landscapes may offer manifold adaptation and mitigation options, in addition to the cultural values they provide. Thus, finding the right financial instruments that would present incentives to land managers to support multifunctional tree crops represents the key to sustainable land management (Hernández-Morcillo et al. 2018). However, considering the increasing pressures, traditional systems that are typically centred on one dominant tree species may be at risk under changing climatic conditions. Introducing a mix of profitable tree-crop species as a crucial component of agroforestry systems (e.g. combined with pastoralism) may offer a way forward towards sustainability. Such traditional and novel systems should be sophisticatedly designed and carefully managed for diversity, profitability and multifunctionality. Emerging questions are: how can the attractiveness of sustainable landscape management be enhanced for locals? And which will be the incentives supporting this?

\section{Limitations}

Our study has covered some of the most iconic tree crops that shape landscapes and are important for human livelihoods in the Mediterranean region. We have utilised a novel approach to analyse and compare the processes and drivers of tree-crop landscapes, hence some limitations of our method need to be considered. We selected three important tree crops that occur at the landscape scale in the Mediterranean region, but other tree crops, for example pine nuts or almonds (Salas-Salvadó et al. 2011), have yet to be considered. Akin to other studies of landscape history (Frattaroli et al. 2014; Turner et al. 2018), published material on the historic development of our study landscapes remains limited, especially as regards those landscapes in the Middle Eastern and North African part of the Mediterranean Basin. Even if there are no natural risks named in certain periods, this does not necessarily mean the absence of these drivers. The authors of the literature that we used could have regarded them as not relevant for their publication. In particular, there is scant information available on the periods of continuity. Furthermore, there may be an inherent 
trade-off between our wish to generalise findings across time and space and the consideration of the complexity of these landscape histories. This complicates the unravelling of processes, driving forces, challenges and solutions of the system (in this case the landscape) because there are many interdependencies across scales (Muñoz-Rojas et al. 2019). Given that our study has been based on a review of primary literature, biases in the identification of relevant drivers of change or in the assessment of processes in primary sources will have translated into similar biases in our study. Furthermore, our cross-site comparative approach has implied that we could not use literature published in local languages (with the exception of Spanish), potentially presenting another source of bias. Especially for the southern fringe of the Mediterranean Basin, there is little English language information about landscape history available. We attempted to reduce these biases via triangulation between different sources concerning each study landscape and by performing additional interviews with local landscape experts.

\section{Conclusions}

Global challenges raise the question of and the need for sustainable landscape management, with agroforestry likely to play a key role. In this study, we have found that many landscapes across the Mediterranean Basin have a long history of biodiverse and sustainable tree-crop systems, although they have undergone substantial changes over time. Our analysis of nine tree-crop landscapes in the Mediterranean Basin offers the following key lessons for future sustainable landscape management:

- Landscape history enables us to learn lessons for future sustainable landscape management. It points to the inherent complexity of landscapes, which must be embraced to guide land uses towards greater sustainability.

- Driving forces mostly appear in bundles and interdependencies across natural, political technological, sociocultural and economic factors, calling for a multi-sectorial and holistic approach to landscape management. However, in some cases single drivers, such as political restrictions or civil strife, can transform landscapes and may require particular attention.

- Profitability is a key driver for the existence and the persistence of tree-crop landscapes.

- Cultural and social drivers play an important role for landscape management, but they have not always been fully acknowledged.

- Tree-crop histories present considerable potential for multifunctional and diverse systems to cope with future challenges, compared to forestry or annual cropping systems.
Acknowledgements Open Access funding provided by Projekt DEAL. This research has been funded by the Deutsche Forschungsgemeinschaft (DFG, German Research Foundation), project number 426675955. We thank the following experts for providing valuable case study information: Sana Dallali, Silvo-Pastoral Institute, Tabarka University of Jendouba, Tunisia, on cork oak landscapes in Tunisia; Jeffrey Wall, Department of Natural Resources, Cornell University, Ithaca, USA, on chestnut landscapes in Turkey; and Ulrich Deil, Institute of Biology II, University of Freiburg, Germany, on olive landscapes in Morocco. This study contributes to the Global Land Programme (www.glp.earth) and the Programme on Ecosystem Change and Society (www.pecs-science.org).

Open Access This article is licensed under a Creative Commons Attribution 4.0 International License, which permits use, sharing, adaptation, distribution and reproduction in any medium or format, as long as you give appropriate credit to the original author(s) and the source, provide a link to the Creative Commons licence, and indicate if changes were made. The images or other third party material in this article are included in the article's Creative Commons licence, unless indicated otherwise in a credit line to the material. If material is not included in the article's Creative Commons licence and your intended use is not permitted by statutory regulation or exceeds the permitted use, you will need to obtain permission directly from the copyright holder. To view a copy of this licence, visit http://creativecommons.org/licenses/by/4.0/.

\section{References}

Acha A, Newing HS (2015) Cork oak landscapes, promised or compromised lands? A case study of a traditional cultural landscape in Southern Spain. Hum Ecol 43(4):601-611. https://doi. org/10.1007/s10745-015-9768-7

Agnoletti M (2007) The degradation of traditional landscape in a mountain area of Tuscany during the 19th and 20th centuries: implications for biodiversity and sustainable management. For Ecol Manag 249(1-2):5-17. https://doi.org/10.1016/j.forec o.2007.05.032

Antrop M (2005) Why landscapes of the past are important for the future. Landsc Urban Plan 70(1-2):21-34. https://doi. org/10.1016/j.landurbplan.2003.10.002

Aumeeruddy-Thomas Y, Moukhli A, Haouane H, Khadari B (2017) Ongoing domestication and diversification in grafted oliveoleaster agroecosystems in Northern Morocco. Reg Environ Change 17(5):1315-1328. https://doi.org/10.1007/s1011 3-017-1143-3

Avanzato D (ed) (2009) Following chestnut footprints (Castanea spp.). Cultivation and culture, folklore and history, traditions and uses. Scripta horticulturae, vol 9. ISHS, Leuven

Beniston M, Stephenson DB, Christensen OB, Ferro CAT, Frei C, Goyette S, Halsnaes K, Holt T, Jylhä K, Koffi B, Palutikof J, Schöll R, Semmler T, Woth K (2007) Future extreme events in European climate: an exploration of regional climate model projections. Clim Change 81:71-95. https://doi.org/10.1007/s10584-006-9226-z

Benoit G, Comeau A (2005) A sustainable future for the Mediterranean: the Blue Plan's environment and development outlook. Earthscan, London

Black A, Strand E, Wright G, Scott M, Morgan P, Watson C (1998) Land use history at multiple scapes: implications for conservation planning. Landsc Urban Plan 43:49-63

Blondel J (2006) The ‘design' of Mediterranean landscapes: a millennial story of humans and ecological systems during the historic period. Hum Ecol 34(5):713-729. https://doi.org/10.1007/s1074 5-006-9030-4 
Blondel J (2010) Mediterranean region: biological diversity in space and time, 2nd edn. Oxford University Press, New York

Bozoglu M, Baser U, Alhas Eroglu N, Kiliz Topuz B (2019) Developments in the chestnut market of Turkey. KSÜ Tar Doga Derg 22(1):19-25. https://doi.org/10.18016/ksutarimdoga.vi.430319

Bugalho MN, Caldeira MC, Pereira JS, Aronson J, Pausas JG (2011) Mediterranean cork oak savannas require human use to sustain biodiversity and ecosystem services. Front Ecol Environ 9(5):278-286. https://doi.org/10.1890/100084

Buonincontri MP, Saracino A, Di Pasquale G (2015) The transition of chestnut (Castanea sativa Miller) from timber to fruit tree: cultural and economic inferences in the Italian peninsula. Holocene 25(7):1111-1123. https://doi.org/10.1177/0959683615580198

Bürgi M, Hersperger AM, Schneeberger N (2004) Driving forces of landscape change-current and new directions. Landsc Ecol 19:857-868

Campos P, Daly-Hassen H, Ovando P (2007) Cork oak forest management in Spain and Tunisia: two case studies of conflicts between sustainability and private income. Int For Rev 9(2):610-626. https ://doi.org/10.1505/ifor.9.2.610

Campos P, Daly-Hassen H, Oviedo JL, Ovando P, Chebil A (2008) Accounting for single and aggregated forest incomes: application to public cork oak forests in Jerez (Spain) and Iteimia (Tunisia). Ecol Econ 65(1):76-86. https://doi.org/10.1016/j.ecole con.2007.06.001

Campos P, Ovando P, Chebil A, Daly-Hassen H (2014) Cork oak woodland conservation and household subsistence economy challenges in northern Tunisia. In: Aronson J, Pereira JS, Pausas JG (eds) Cork oak woodlands on the edge. Island Press, Washington DC

Cecchini M, Zambon I, Pontrandolfi A, Turco R, Colantoni A, Mavrakis A, Salvati L (2019) Urban sprawl and the 'olive' landscape: sustainable land management for 'crisis' cities. GeoJournal 84(1):237-255. https://doi.org/10.1007/s10708-018-9848-5

Costa A, Pereira H, Madeira M (2009) Landscape dynamics in endangered cork oak woodlands in Southwestern Portugal (19582005). Agrofor Syst 77(2):83-96. https://doi.org/10.1007/s1045 7-009-9212-3

Crews TE, Blesh J, Culman SW, Hayes RC, Jensen ES, Mack MC, Peoples MB, Schipanski ME (2016) Going where no grains have gone before: from early to mid-succession. Agric Ecosyst Environ 223:223-238. https://doi.org/10.1016/j.agee.2016.03.012

Daoui K, Fatemi ZEA (2014) Agroforestry systems in Morocco: the case of olive tree and annual crops association in Saiis region. In: Behnassi M, Shahid SA, Mintz-Habib N (eds) Science, policy and politics of modern agricultural system, vol 94. Springer, Dordrecht, pp 281-289

Flinzberger L, Zinngrebe Y, Plieninger T (2020) Labelling in Mediterranean agroforestry landscapes: a Delphi study on relevant sustainability indicators. Sust Sci. https://doi.org/10.1007/s1162 5-020-00800-2

Fonseca HA (2003) Agrarian elites and economic growth in nineteenthcentury Portugal: the example of the Alentejo in the Liberal Era (1850-1910). Soc Hist 28(2):202-226

Frattaroli AR, Ciabò S, Pirone G, Spera DM, Marucci A, Romano B (2014) The disappearance of traditional agricultural landscapes in the Mediterranean basin. The case of almond orchards in Central Italy. Plant Sociol 51(2):3-15

Grove AT, Rackham O (2001) The nature of Mediterranean Europe: an ecological history. Yale University Press, New Haven

Guzmán Álvarez JR (2016) The image of a tamed landscape: dehesa through history in Spain. Cult Hist Dig J 5(1):e003. https://doi. org/10.3989/chdj.2016.003

Hernández-Morcillo M, Burgess P, Mirck J, Pantera A, Plieninger T (2018) Scanning agroforestry-based solutions for climate change mitigation and adaptation in Europe. Environ Sci Policy 80:44-52. https://doi.org/10.1016/j.envsci.2017.11.013
Howlett DS, Moreno G, Mosquera Losada MR, Nair PKR, Nair VD (2011) Soil carbon storage as influenced by tree cover in the Dehesa cork oak silvopasture of central-western Spain. J Environ Monit 13(7):1897-1904. https://doi.org/10.1039/c1em10059a

Infante Amate J (2012) La ordemacion des espacio agrario en economias preindutriales. El caso del cultivo del olivo el sur de Espana. El Futuro del Pasado 3:403-438

Infante-Amate $\mathrm{J}$ (2012) The ecology and history of the Mediterranean olive grove: the Spanish great expansion, 1750-2000. Rural Hist 23(2):161-184. https://doi.org/10.1017/S0956793312000052

Infante-Amate J, de Molina MG (2013) The socio-ecological transition on a crop scale: the case of olive orchards in Southern Spain (1750-2000). Hum Ecol 41(6):961-969. https://doi.org/10.1007/ s10745-013-9618-4

Infante-Amate J, Villa I, Aguilera E, Torremocha E, Guzmán G, Cid A, González de Molina M (2016) The making of olive landscapes in the South of Spain. A history of continuous expansion and intensification. In: Agnoletti M, Emanueli F (eds) Biocultural diversity in Europe, vol 5. Springer, Cham, pp 157-179

Jepsen MR, Kuemmerle T, Müller D, Erb K, Verburg PH, Haberl H, Vesterager JP, Andrič M, Antrop M, Austrheim G, Björn I, Bondeau A, Bürgi M, Bryson J, Caspar G, Cassar LF, Conrad E, Chromý P, Daugirdas V, van Eetvelde V, Elena-Rosselló R, Gimmi U, Izakovicova Z, Jančák V, Jansson U, Kladnik D, Kozak J, Konkoly-Gyuró E, Krausmann F, Mander Ü, McDonagh J, Pärn J, Niedertscheider M, Nikodemus O, Ostapowicz K, PérezSoba M, Pinto-Correia T, Ribokas G, Rounsevell M, Schistou D, Schmit C, Terkenli TS, Tretvik AM, Trzepacz P, Vadineanu A, Walz A, Zhllima E, Reenberg A (2015) Transitions in European land-management regimes between 1800 and 2010. Land Use Policy 49:53-64. https://doi.org/10.1016/j.landusepol.2015.07.003

Jones N, de Graaff J, Rodrigo I, Duarte F (2011) Historical review of land use changes in Portugal (before and after EU integration in 1986) and their implications for land degradation and conservation, with a focus on Centro and Alentejo regions. Appl Geogr 31(3):1036-1048. https://doi.org/10.1016/j.apgeog.2011.01.024

Kholy ME (ed) (2012) Following olive footprints (Olea europaea L.). Cultivation and culture, folklore and history, traditions and uses. Scripta horticulturae, vol 13. ISHS, Leuven

Kizos T, Dalaka A, Petanidou T (2010) Farmers' attitudes and landscape change: evidence from the abandonment of terraced cultivations on Lesvos, Greece. Agric Hum Values 27(2):199-212. https ://doi.org/10.1007/s10460-009-9206-9

Kizos T, Koulouri M (2006) Agricultural landscape dynamics in the Mediterranean: Lesvos (Greece) case study using evidence from the last three centuries. Environ Sci Policy 9(4):330-342. https:// doi.org/10.1016/j.envsci.2006.02.002

Kizos T, Koulouri M (2010) Same land cover, same land use at the large scale, different landscapes at the small scale: landscape change in olive plantations on Lesvos island, Greece. Landsc Res 35(4):449-467. https://doi.org/10.1080/01426390802048297

Kizos T, Plieninger T (2008) Agroforestry systems change in the Mediterranean: some evidence from Greek and Spanish examples. In: International conference "studying, modeling and sense making of planet Earth", Mytilene, 1-6 June 2008

Kmoch L, Pagella T, Palm M, Sinclair F (2018) Using local agroecological knowledge in climate change adaptation: a study of treebased options in northern Morocco. Sustainability 10(10):3719. https://doi.org/10.3390/su10103719

Kremen C, Iles A, Bacon C (2012) Diversified farming systems: an agroecological, systems-based alternative to modern industrial agriculture. Ecol Soc 17(4):44. https://doi.org/10.5751/ES-05103-170444

Lasanta T, Arnáez J, Pascual N, Ruiz-Flaño P, Errea MP, Lana-Renault $\mathrm{N}$ (2017) Space-time process and drivers of land abandonment in Europe. CATENA 149:810-823. https://doi.org/10.1016/j.caten a.2016.02.024 
Mansoura AB, Garchi S, Daly H (2001) Analyzing forest users' destructive behavior in northern Tunisia. Land Use Policy 18(2):153-163. https://doi.org/10.1016/S0264-8377(01)00004-7

Marathianou M, Kosmas C, Gerontidis S, Detsis V (2000) Landuse evolution and degradation in Lesvos (Greece): a historical approach. Land Degrad Dev 11(1):63-67

Martín-López B et al (2016) Ecosystem services supplied by Mediterranean Basin ecosystems. In: Potschin M, Haines-Young R, Fish R, Turner RK (eds) Handbook on ecosystem services. Routledge, London, pp 405-414

McIntyre BD (2008) International assessment of agricultural science and technology. Island Press, Washington, D.C., Eurospan [distributor], London

Michon G (2011) Revisiting the resilience of chestnut forests in Corsica: from social-ecological systems theory to political ecology. Ecol Soc 16(2):5. https://doi.org/10.5751/ES-04087-160205

Mouillot F, Paradis G, Andrei-Ruiz M-C, Quilichini A (2008) Corsica. In: Mannion AM, Pungetti G, Vogiatzakis IN (eds) Mediterranean island landscapes. Natural and cultural approaches, vol 9. Springer, New York, pp 220-244

Mouillot F, Ratte J-P, Joffre R, Mouillot D, Rambal SA (2005) Longterm forest dynamic after land abandonment in a fire prone Mediterranean landscape (central Corsica, France). Landsc Ecol 20(1):101-112. https://doi.org/10.1007/s10980-004-1297-5

Muñoz-Rojas J, Pinto-Correia T, Hvarregaard Thorsoe M, Noe E (2019) The Portuguese Montado: a complex system under tension between different land use management paradigms. Silvicult Manag Conserv. https://doi.org/10.5772/intechopen.86102

Olea L, San Miguel-Ayanz A (2006) The Spanish dehesa. A traditional Mediterranean silvopastoral system linking production and nature conservation. Grassl Sci Eur 11:3-13

Palang H, Helmfrid S, Antrop M, Alumäe H (2005) Rural landscapes: past processes and future strategies. Landsc Urban Plan 70(12):3-8. https://doi.org/10.1016/j.landurbplan.2003.10.001

Perry PJ (1967) Economy, landscape and society in La Castagniccia (Corsica) since the late eighteenth century. Trans Inst Br Geogr 41:209. https://doi.org/10.2307/621337

Pezzi G, Lucchi E, Maresi G, Ferretti F, Viaggi D, Frascaroli F (2017) Abandonment or survival? Understanding the future of Castanea sativa stands in function of local attitude (Northern Apennine, Italy). Land Use Policy 61:564-574. https://doi.org/10.1016/j. landusepol.2016.10.049

Pezzi G, Maresi G, Conedera M, Ferrari C (2011) Woody species composition of chestnut stands in the Northern Apennines: the result of 200 years of changes in land use. Landsc Ecol 26(10):14631476. https://doi.org/10.1007/s10980-011-9661-8

Pinto-Correia T, Mascarenhas J (1999) Contribution to the extensification/intensfication debate: new trends in the Portuguese montado. Landsc Urban Plan 46:125-131

Pinto-Correia T, Muñoz-Rojas J, Thorsøe MH, Noe EB (2019) Governance discourses reflecting tensions in a multifunctional land use system in decay; tradition versus modernity in the Portuguese Montado. Sustainability 11(12):3363. https://doi.org/10.3390/ su11123363

Pinto-Correia T, Vos W (2004) Multifunctionality in Mediterranean landscapes-past and future. In: Jongman RHG (ed) The new dimensions of the European landscape. Springer, Berlin, pp 135-164

Plieninger T, Draux H, Fagerholm N, Bieling C, Bürgi M, Kizos T, Kuemmerle T, Primdahl J, Verburg PH (2016) The driving forces of landscape change in Europe: a systematic review of the evidence. Land Use Policy 57:204-214. https://doi.org/10.1016/j. landusepol.2016.04.040
Plieninger T, Hartel T, Martín-López B, Beaufoy G, Bergmeier E, Kirby K, Montero MJ, Moreno G, Oteros-Rozas E, van Uytvanck J (2015) Wood-pastures of Europe: geographic coverage, social-ecological values, conservation management, and policy implications. Biol Conserv 190:70-79. https://doi.org/10.1016/j. biocon.2015.05.014

Ramos Guedes-Lafargue M, Franzini R, Laigret F (2005) Evaluation of INRA chestnut interspecific hybrids. Acta Hortic. https://doi. org/10.17660/ActaHortic.2005.693.40

Roossinck MJ, García-Arenal F (2015) Ecosystem simplification, biodiversity loss and plant virus emergence. Curr Opin Virol 10:5662. https://doi.org/10.1016/j.coviro.2015.01.005

Rusch A, Chaplin-Kramer R, Gardiner MM, Hawro V, Holland J, Landis D, Thies C, Tscharntke T, Weisser WW, Winqvist C, Woltz M, Bommarco R (2016) Agricultural landscape simplification reduces natural pest control: a quantitative synthesis. Agric Ecosyst Environ 221:198-204. https://doi.org/10.1016/j. agee.2016.01.039

Salas-Salvadó J, Casas-Agustench P, Salas-Huetos A (2011) Cultural and historical aspects of Mediterranean nuts with emphasis on their attributed healthy and nutritional properties. Nutr Metab Cardiovasc Dis NMCD 21(Suppl 1):S1-6. https://doi.org/10.1016/j. numecd.2010.10.013

San Roman Sanz A, Fernandez C, Mouillot F, Ferrat L, Istria D, Pasqualini V (2013) Long-term forest dynamics and land-use abandonment in the Mediterranean mountains, Corsica, France. Ecol Soc 18(2):38. https://doi.org/10.5751/ES-05556-180238

Sanz MJ, Vente JL de, Chotte J-L, Bernoux M, Kust G, Ruiz I, Almagro M, Alloza JA, Vallejo R, Castillo V, Hebel A, Akhtar-Schuster $M$ (2017) Sustainable land management contribution to successful land-based climate change adaptation and mitigation: a report of the Science-Policy Interface. United Nations Convention to Combat Desertification (UNCCD), Bonn, Germany

Serdar U, Akyuz B, Ceyhan V, Hazneci K, Mert C, Er R, Ertan E, Coskuncu KS, Uylaşer V (2014) An overview of chestnut production in Turkey. Acta Hortic 1019:211-214. https://doi. org/10.17660/ActaHortic.2014.1019.31

Stockwell P (1947) The culture of cork oak in Spain. Econ Bot 1(4):381-388

Strijker D (2005) Marginal lands in Europe-causes of decline. Basic Appl Ecol 6(2):99-106. https://doi.org/10.1016/j. baae.2005.01.001

Tagliaferri G, Di Lonardo S (2016) Chestnut management practice as tool for natural and cultural landscaping. In: Agnoletti M, Emanueli F (eds) Biocultural diversity in Europe, vol 5. Springer International Publishing, Cham, pp 353-367

Turner S, Bolòs J, Kinnaird T (2018) Changes and continuities in a Mediterranean landscape: a new interdisciplinary approach to understanding historic character in western Catalonia. Landsc Res 43(7):922-938. https://doi.org/10.1080/01426397.2017.1386778

UNEP/MAP (2016) Mediterranean strategy for sustainable development 2016--2025, Valbonne. Plan Bleu, Regional Activity Centre

Vicente ÁM, Alés RF (2006) Long term persistence of dehesas. Evidences from history. Agrofor Syst 67(1):19-28. https://doi. org/10.1007/s10457-005-1110-8

Wall J, Köse C, Köse N, Okan T, Aksoy EB, Jarvis D, Allred S (2019) The role of traditional livelihood practices and local ethnobotanical knowledge in mitigating chestnut disease and pest severity in Turkey. Forests 10(7):571. https://doi.org/10.3390/f10070571

Zagaria C, Schulp CJE, Kizos T, Gounaridis D, Verburg PH (2017) Cultural landscapes and behavioral transformations: an agentbased model for the simulation and discussion of alternative 
landscape futures in East Lesvos, Greece. Land Use Policy 65:2644. https://doi.org/10.1016/j.landusepol.2017.03.022

Zapata S (ed) (2009) Cork oak woodlands and cork industry: present, past and future. Museu del Suro de Palafrugell, Palafrugell

Zdruli P (2014) Land resources of the Mediterranean: status, pressures, trends and impacts on future regional development. Land Degrad Dev 25(4):373-384. https://doi.org/10.1002/ldr.2150
Publisher's Note Springer Nature remains neutral with regard to jurisdictional claims in published maps and institutional affiliations. 